\title{
Tidal influence on Rutford Ice Stream, West Antarctica: observations of surface flow and basal processes from closely spaced GPS and passive seismic stations
}

\author{
G. AĐALGEIRSDÓTTIR, ${ }^{1}$ A.M. SMITH, ${ }^{2}$ T. MURRAY, ${ }^{1}$ M.A. KING, ${ }^{3}$ K. MAKINSON, ${ }^{2}$ \\ K.W. NICHOLLS, ${ }^{2}$ A.E. BEHAR ${ }^{4}$ \\ ${ }^{1}$ Department of Geography, University of Wales Swansea, Singleton Park, Swansea SA2 8PP, UK \\ E-mail: gua@dmi.dk \\ ${ }^{2}$ Physical Sciences Division, British Antarctic Survey, Natural Environment Research Council, Madingley Road, \\ Cambridge CB3 OET, UK \\ ${ }^{3}$ School of Civil Engineering and Geosciences, Cassie Building, University of Newcastle upon Tyne, \\ Newcastle upon Tyne NE1 7RU, UK \\ ${ }^{4}$ Robotic Vehicles Group, Jet Propulsion Laboratory, California Institute of Technology, 4800 Oak Grove Drive, \\ Pasadena, California 91109-8099, USA
}

\begin{abstract}
High-resolution surface velocity measurements and passive seismic observations from Rutford Ice Stream, West Antarctica, $40 \mathrm{~km}$ upstream from the grounding line are presented. These measurements indicate a complex relationship between the ocean tides and currents, basal conditions and ice-stream flow. Both the mean basal seismicity and the velocity of the ice stream are modulated by the tides. Seismic activity increases twice during each semi-diurnal tidal cycle. The tidal analysis shows the largest velocity variation is at the fortnightly period, with smaller variations superimposed at diurnal and semi-diurnal frequencies. The general pattern of the observed velocity is two velocity peaks during each semi-diurnal tidal cycle, but sometimes three peaks are observed. This pattern of two or three peaks is more regular during spring tides, when the largest-amplitude velocity variations are observed, than during neap tides. This is the first time that velocity and level of seismicity are shown to correlate and respond to tidal forcing as far as $\mathbf{4 0} \mathrm{km}$ upstream from the grounding line of a large ice stream.
\end{abstract}

\section{INTRODUCTION}

Ice from the interior of Antarctica is delivered to ice shelves and oceans through fast-flowing ice streams and glaciers. The ice streams flow up to two orders of magnitude faster than the surrounding ice and they are the most dynamic components of the ice-sheet system. These fast-flowing ice streams provide a connection between the floating ice shelves, which have relatively short-period responses, and the slowermoving inland ice sheet with a longer response time.

Global positioning system (GPS) receivers, which use data from satellites and do not need a visible reference point, are now commonly used in glaciological fieldwork. This method, with high temporal resolution and rigorous processing methods (King, 2004), has provided the breakthrough required to observe short-term changes in ice flow and to study ice dynamics on timescales that have not previously been accessible (e.g. O'Neel and others, 2001; Doake and others, 2002; Anandakrishnan and others, 2003; Bindschadler and others, 2003b; Legrésy and others, 2004; Gudmundsson, 2006). In addition, the deployment of passive seismic recording stations that monitor microearthquakes has proven to be valuable in mapping ice-stream basal conditions (Blankenship and others, 1987; Anandakrishnan and Bentley, 1993; Smith, 2006). Combining the two observation methods is a novel way to enhance the understanding of ice-stream dynamics and to relate what happens at the bed to the resulting flow regime.

It is now possible to observe highly variable flow dynamics and basal conditions on the ice streams in Antarctica and there appear to be some similarities, but also differences, between the ice streams that have been measured. On the Siple Coast, several ice-stream flow dynamics have been characterized. The speed of Bindschadler Ice Stream (former Ice Stream D) has been measured to vary by a factor of three over the course of a day (Anandakrishnan and others, 2003). At the grounding line the ice stream speeds up during falling tide and slows during rising tide. This effect was observed to propagate upstream at $5.6 \mathrm{~m} \mathrm{~s}^{-1}$ and can be detected at least $80 \mathrm{~km}$ upstream. On the ice plain at the mouth of Whillans Ice Stream (former Ice Stream B), Bindschadler and others (2003b) showed a strong stick-slip motion behaviour, where the ice stream accelerates to speeds greater than $1 \mathrm{~m} \mathrm{~h}^{-1}$ (30 times faster than normal) in as little as $30 \mathrm{~s}$. This flow behaviour has been modelled with varying ocean back pressure, as the adjacent ice shelf flexes with the tides (Bindschadler and others, 2003a). On Kamb Ice Stream (former Ice Stream C), there is an anticorrelation between mean basal seismicity (averaged over many days) and mean flow speed (Anandakrishnan and Alley, 1997a). On shorter timescales, periods of basal seismic activity, at a site $10 \mathrm{~km}$ from the grounding line, correlate with low tide on the ice shelf. In this case, the tidal forcing travels up the ice stream at $\sim 1.6 \mathrm{~m} \mathrm{~s}^{-1}$ (Anandakrishnan and Alley, 1997b). On the opposite side of West Antarctica, where ice flows into the Filchner-Ronne Ice Shelf, the surface velocity of Rutford Ice Stream has been measured to vary with a fortnightly period up to $40 \mathrm{~km}$ upstream from the grounding line; close to the grounding line the variation is about $20 \%$ (Gudmundsson, 2006). The longest available velocity record, of $\sim 2$ years, reveals that this variability also occurs at annual and semi-annual periods with higher and more variable velocity 


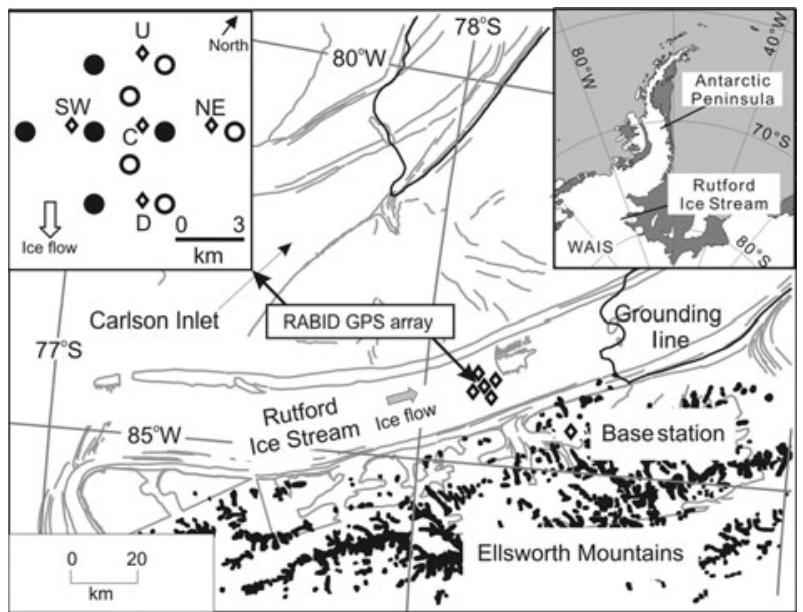

Fig. 1. Site map showing Rutford Ice Stream flowing into the Ronne Ice Shelf and the neighbouring Carlson Inlet. The five GPS antennas were located $\sim 40 \mathrm{~km}$ upstream from the grounding line, and the reference station is $31 \mathrm{~km}$ from the GPS array. The left inset shows the geometry of the measurement array. Diamonds indicate the geographic location of the GPS receivers, filled circles the passive seismic receivers that ran throughout the period shown in Figure 4 and open circles the ones that ran during only the first part of the experiment. The seismic and GPS receivers were not run simultaneously (see text for details).

around equinoxes (21 March and 22 September) compared to variations around solstices (21 June and 21 December), when most measurements are made (Murray and others, 2007). These observations indicate that ice streams are sensitive to sea level with a short response time and could respond rapidly to changes in the mean sea level or any consequent changes in tidal range.

In this paper, surface velocities derived from GPS position measurements and passive seismic data from Rutford Ice Stream, $40 \mathrm{~km}$ upstream from the grounding line, are presented. The GPS measurements were recorded during a 6 week period in 2004/05, and the passive seismic data 7 years previously during a 4 week period in 1997 . These data show a complex interaction between ocean tides, basal condition and ice-stream flow speed.

\section{LOCATION}

Rutford Ice Stream is part of the West Antarctic ice sheet (WAIS). It flows in a south-southeast direction until it discharges into the Ronne Ice Shelf (Fig. 1). It is estimated that the area that feeds the Rutford Ice Stream is $\sim 49000 \mathrm{~km}^{2}$, which includes the northern part of the Ellsworth Mountains and borders the drainage basins of Pine Island Glacier, Carlson Inlet and Evans Ice Stream (Doake and others, 2001). The thickness of the ice stream is $\sim 2 \mathrm{~km}$, and the ice is grounded below sea level along its entire length. The surface elevation of the grounded areas is $>30 \mathrm{~m}$ above that needed for hydrostatic equilibrium (Doake and others, 1987).

Ground and airborne radio-echo sounding measurements on the ice stream have revealed variable ice thickness; the bed across the ice stream is W-shaped, with deep trenches running parallel to the flow (Stephenson and Doake, 1982). The location of the grounding line has been found by use of tiltmeters and flexure analysis (Stephenson and Doake,

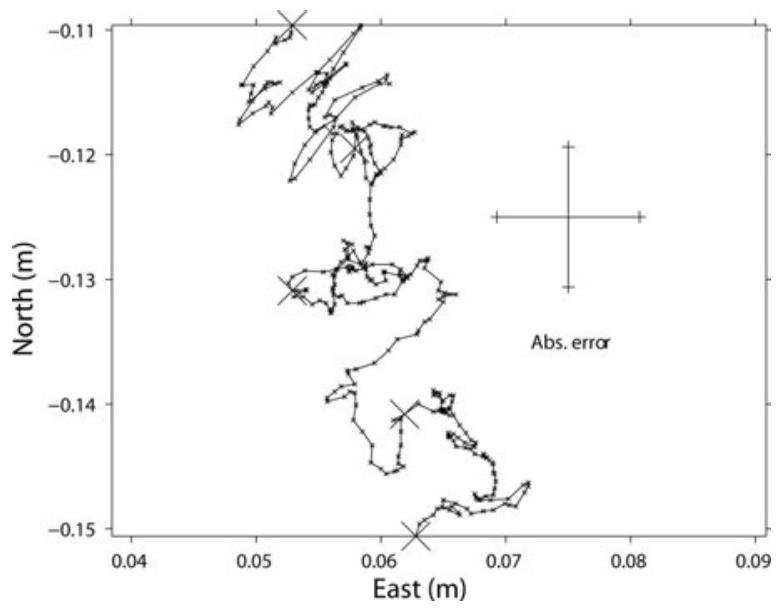

Fig. 2. An example of the computed path of antenna D during 1 hour. Ice flow is from top to bottom. The estimated absolute accuracy in the horizontal direction is shown with error bars. A solution is computed every $10 \mathrm{~s}$; larger crosses are drawn on the path every $15 \mathrm{~min}$.

1982; Stephenson, 1984; Smith, 1991) and synthetic aperture radar interferometry (Rignot, 1998). The ice-stream bed at the grounding line is $\sim 1500 \mathrm{~m}$ below sea level and the basal topography is complicated. There is a pinning point on which the ice rests in the centre of the ice stream, which coincides with a topographic high in the bed (Doake and others, 1987), and interferograms reveal areas of partial grounding on the ice shelf (Rignot, 1998).

Repeated seismic surveys on the ice stream, undertaken in the same area as the measurements presented here, have shown that there are both spatial (Smith, 1997a, b) and temporal (Smith and others, 2007) variations in the basal conditions. Despite a relatively steady ice-flow rate, rapid erosion, drumlin formation and changing hydrology have been observed over a short period of time $(<6$ years) (Smith and others, 2007).

\subsection{GPS array}

A network of five GPS receivers was installed $\sim 40 \mathrm{~km}$ upstream from the grounding line of Rutford Ice Stream during the 2004/05 field season. The data were collected from 17 December 2004 to 10 February 2005. A reference station installed on rock $31 \mathrm{~km}$ away in the Ellsworth Mountains measured continuously for 34.5 days $(31$ December to 3 February). Data from the reference station enabled those from the ice-stream receivers to be processed to a high accuracy, and in this paper we consider only data recorded whilst the reference station was in operation. The locations of the field site, the reference station and the ice-stream stations are shown in Figure 1. The other four stations were established directly upstream, downstream and in both directions across the ice stream, each one $\sim 3 \mathrm{~km}$ from the central site. This geometry was designed primarily for a passive seismic array in which some stations were located at the same sites as the GPS receivers. All the GPS receivers (reference and icestream stations) recorded data at $10 \mathrm{~s}$ intervals. This highresolution sampling rate was chosen in order to be able to resolve possible acceleration to frictionless speed, as observed on Whillans Ice Stream (Bindschadler and others, 2003a, b). 
Table 1. From top to bottom: the along-flowline average velocity $\left(\mathrm{m} \mathrm{a}^{-1}\right.$; estimated error $\left.0.06 \mathrm{~m} \mathrm{a}^{-1}\right)$, the direction of the average velocity (east from north; estimated error $0.01^{\circ}$ ), the standard deviation from mean velocity $\left(\mathrm{m} \mathrm{a}^{-1}\right)$, the percentage of the variance in the velocity record that can be explained by tidal components and the amplitude $\left(\mathrm{m} \mathrm{a}^{-1}\right)$ of the six largest tidal constituents resulting from harmonic analysis of the velocity records. These values are plotted against the corresponding amplitudes of the tidal signal on the ice shelf in Figure 6

Station

U

NE

C

SW

D

\begin{tabular}{|c|c|c|c|c|c|}
\hline Average velocity $\left(\mathrm{m} \mathrm{a}^{-1}\right)$ & 373.88 & 366.85 & 374.33 & 380.28 & 375.68 \\
\hline Direction $\left({ }^{\circ}\right)$ & 154.76 & 152.13 & 153.01 & 154.34 & 151.83 \\
\hline Standard deviation $\left(\mathrm{m} \mathrm{a}^{-1}\right)$ & 18.38 & 20.77 & 19.94 & 20.78 & 22.74 \\
\hline Explained variance (\%) & 86.4 & 71.0 & 80.0 & 82.7 & 81.5 \\
\hline
\end{tabular}

Tidal constant $\left(\mathrm{m} \mathrm{a}^{-1}\right)$

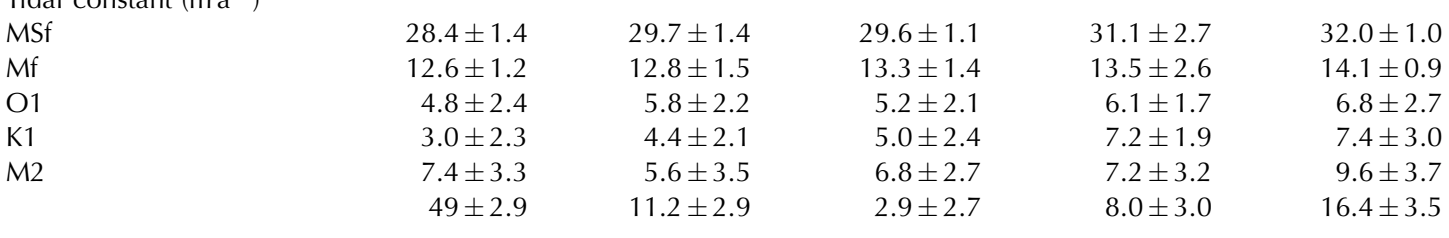

\subsection{Passive seismic array}

Despite considerable effort, no relevant passive seismic data were recorded during the GPS work in the 2004/05 field season. However, a network of passive seismic stations was deployed in the same area during December 1997 (Smith, 2006), and some aspects of those data will be considered alongside the new GPS results. Ten recording stations were established on the ice stream (Fig. 1) and maintained for 13 days. Following a 3 day break in recording, a five-station subset of the first array operated for a further 7 days. Seismic energy at each station was detected by three-component geophones $(20 \mathrm{~Hz}$ natural frequency) and sampled at $2 \mathrm{~ms}$ intervals. Events in which the signal on the vertical channel rose sufficiently above a continuously monitored background level were recorded on Reftek data acquisition system (DAS) data loggers. This triggering algorithm will presumably fail to record the smallest seismic events, but background noise levels in the area are very low and hence the result should give a good relative indication of levels of seismicity over the array.

\section{GPS DATA PROCESSING}

The GPS reference station, which was located in the Ellsworth Mountains (Fig. 1), $31 \mathrm{~km}$ away and $894 \mathrm{~m}$ above the field site, allowed a relative processing procedure to be used. The position of the reference station was determined using the Precise Point Positioning (PPP) approach implemented in the GIPSY/OASIS II software (Zumberge and others, 1997). To ensure that systematic errors were not introduced during the data processing, rigorous processing strategies were adopted (King, 2004). The differential-phase kinematic positioning program, TRACK (part of the GAMIT software package (R.W. King and Y. Bock, unpublished information)), was used to process the continuous GPS data on the ice stream relative to the base station. The motion of each antenna was modelled as a random walk, with a constraint on the epoch-to-epoch motion set to $5-10 \mathrm{~mm}$. GPS formal errors are generally over-optimistic, and hence we compute the uncertainties by examining the detrended coordinate time series computed between the base station and another linearly moving site $\sim 80 \mathrm{~km}$ away on the other side of Rutford Ice Stream. The root-mean-square of this time series suggests a precision of better than $1 \mathrm{~cm}$ (horizontal) and $3 \mathrm{~cm}$ (vertical). Given that this baseline is longer than the baselines to Rutford Ice Stream, we therefore expect the coordinate precisions of the velocity stakes to be better than 1 and $3 \mathrm{~cm}$ in the horizontal and vertical components, respectively. Visual inspection of the horizontal-position time series confirms this. An example of horizontal movement of stake D over 1 hour is shown in Figure 2.

Inspection of the horizontal movement of all the stakes during the whole period (at $10 \mathrm{~s}$ measurement resolution) reveals that the motion is smooth, with no sign of stick-slip behaviour.

The average horizontal velocity of each antenna was computed by linear least squares, fitting a line through the antenna path. The resulting values are presented in Table 1. The flow velocity increases in the downstream direction and also southwest across the ice stream.

The coordinate system for each antenna was then rotated to have the $x$ axis along the mean flow direction, and the time series of position was then detrended by subtracting the mean linear motion. Neither the surface elevation nor the lateral horizontal movement (i.e. perpendicular to the mean flow direction) shows anything other than smooth motion during the recording period. In contrast, the detrended, along-flow horizontal motion (Fig. 3) shows clear, periodic flow variations: a dominant fortnightly variation, with diurnal and semi-diurnal frequencies superimposed upon it. This flow variation is analogous to similar GPS data of horizontal along-flow positions from Rutford Ice Stream that were collected at the grounding line, 10, 20 and $40 \mathrm{~km}$ upstream from the grounding line (Gudmundsson, 2006). The new data therefore confirm that tides have a persistent influence on the flow of the ice stream at least as far as $40 \mathrm{~km}$ upstream from the grounding line. Below we analyze a high-resolution velocity time series derived from these along-flow horizontal motion records.

\section{PASSIVE SEISMIC DATA}

The characteristics and interpretation of the passive seismic data were presented in detail by Smith (2006), including 


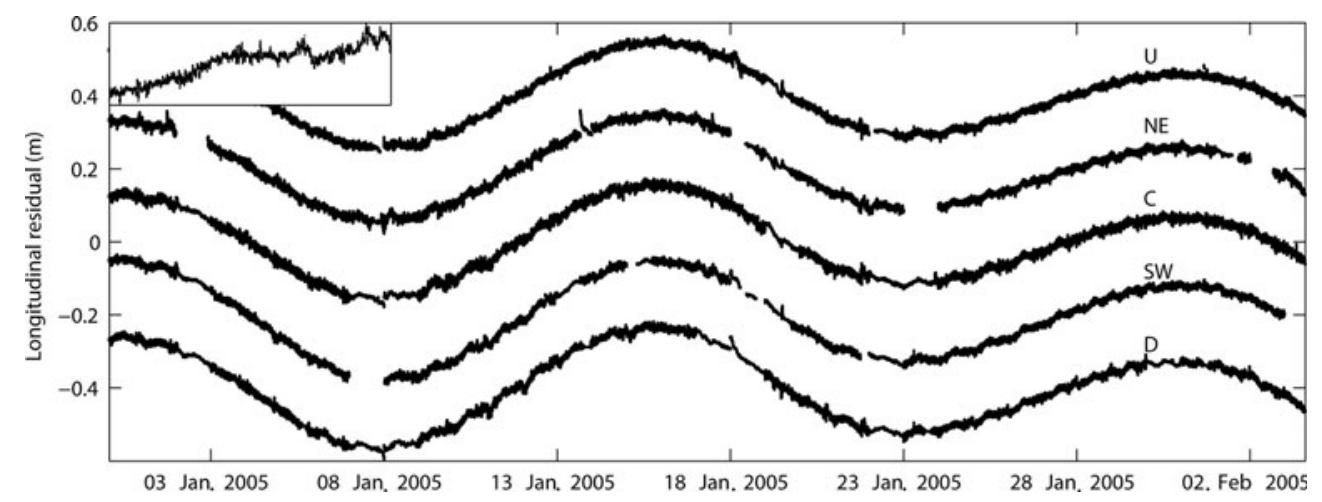

Fig. 3. The detrended inline position of the five antennas showing the fortnightly flow variability of the ice stream. Deviation from mean longitudinal motion is shown: negative values indicate that the antenna has been moving slower than the mean velocity. Top to bottom: $\mathrm{U}, \mathrm{NE}, \mathrm{C}, \mathrm{SW}, \mathrm{D}$. For clarity, curves for NE and SW are shifted +0.2 and $-0.2 \mathrm{~m}$, respectively, and lines for $\mathrm{U}$ and $\mathrm{D}$ are shifted +0.4 and $-0.4 \mathrm{~m}$, respectively. The inset in the top left corner shows 24 hours of data for SW during 10 January 2005.

examples of typical waveforms (see fig. 2 therein). In summary, events from the bed were identified from waveform characteristics (Blankenship and others, 1987; Anandakrishnan and Bentley, 1993) and from the difference in their $\mathrm{P}$ - and S-wave travel times, knowing the ice thickness from seismic reflection surveys and typical seismic velocities in ice ( 3600-3900 $\mathrm{m} \mathrm{s}^{-1}$ for $\mathrm{P}$ waves and $\sim 1700-1950 \mathrm{~m} \mathrm{~s}^{-1}$ for $\mathrm{S}$ waves). For each bed event, this difference in travel times was consistent with $\mathrm{P}$ and $\mathrm{S}$ waves originating from a single event at the ice-stream bed. Events from all other origins were discarded. No bed events could be identified at more than one recording station, and the maximum observed difference in $\mathrm{P}$ - and S-wave travel times indicated a source with an epicentral distance of no greater than $1 \mathrm{~km}$ from the recording station. Hence, the bed events are lowenergy and each station was sensitive only to those occurring within an epicentral radius of $\sim 1 \mathrm{~km}$. This means that all the basal events detected at a given recording station originate within a relatively small area of the bed (radius $1 \mathrm{~km}$ ) centred directly beneath that station. The hourly mean number of basal events was calculated across the whole array (Fig. 4). The seismic events from the ice-stream bed all have similar amplitudes (Smith, 2006), and hence, although the coarse sample rate $(2 \mathrm{~ms})$ precludes a rigorous quantitative analysis of wavelet energies, the number of events detected is still a reasonable indication of the relative levels of elastic energy being released at the bed.

Mean basal seismicity across the array (Fig. 4) shows active periods of a few hours, separated by inactive periods of between 1 hour and 1 day. Basal seismicity varies across the array (Smith, 2006), so the reduced number of stations from 15 December 1997 onwards (five rather than ten) means the basal seismicity magnitude cannot necessarily be compared directly between the two recording periods in Figure 4. However, although the level of seismicity varies, the timing of any relatively active and inactive periods of basal seismicity should be largely independent of the number of stations or their locations. Hence, we concentrate primarily

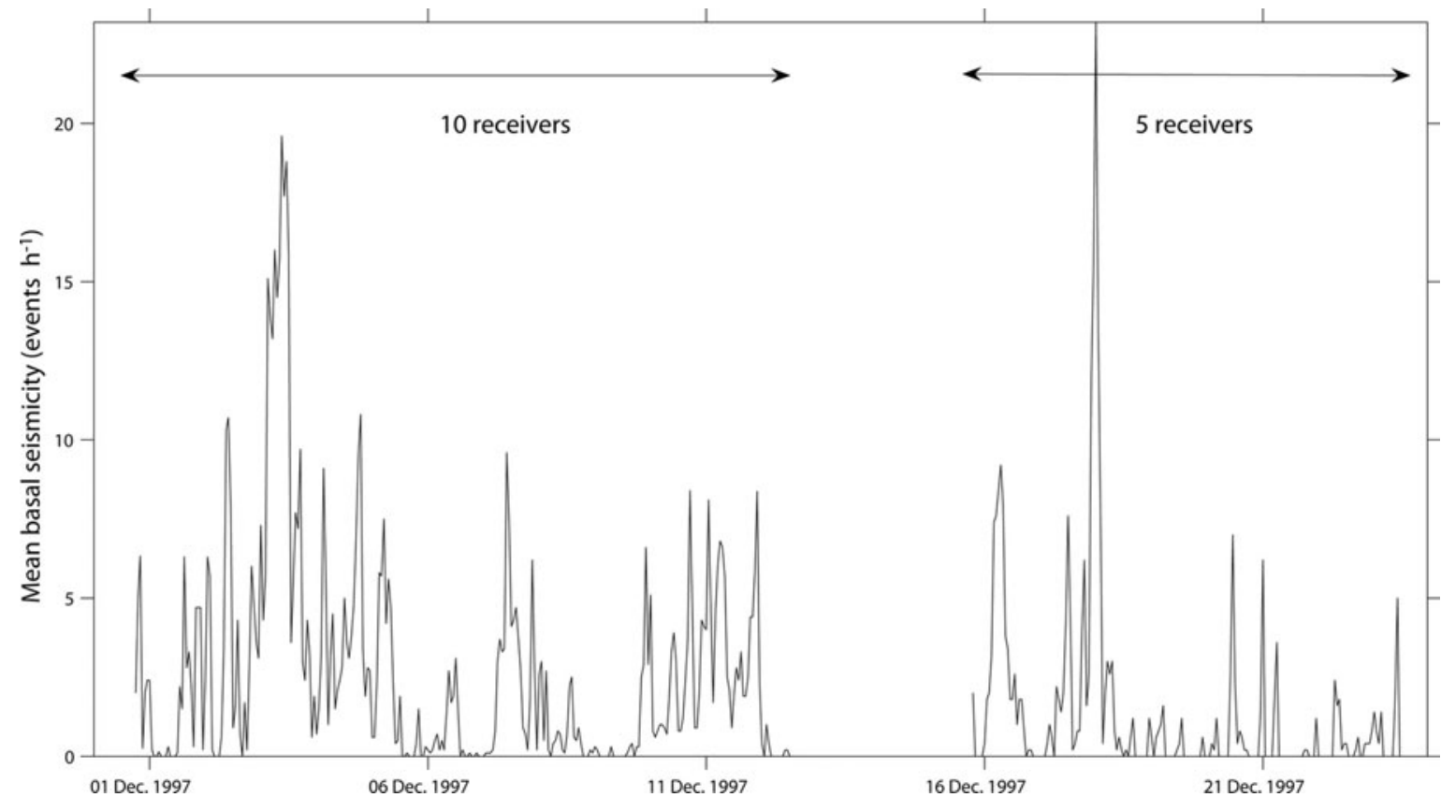

Fig. 4. Mean basal seismicity across the array, showing the number of events per hour recorded at all active stations (ten stations during the first period (30 November 1997 to 12 December 1997), five stations in the second period (15-23 December 1997)). 


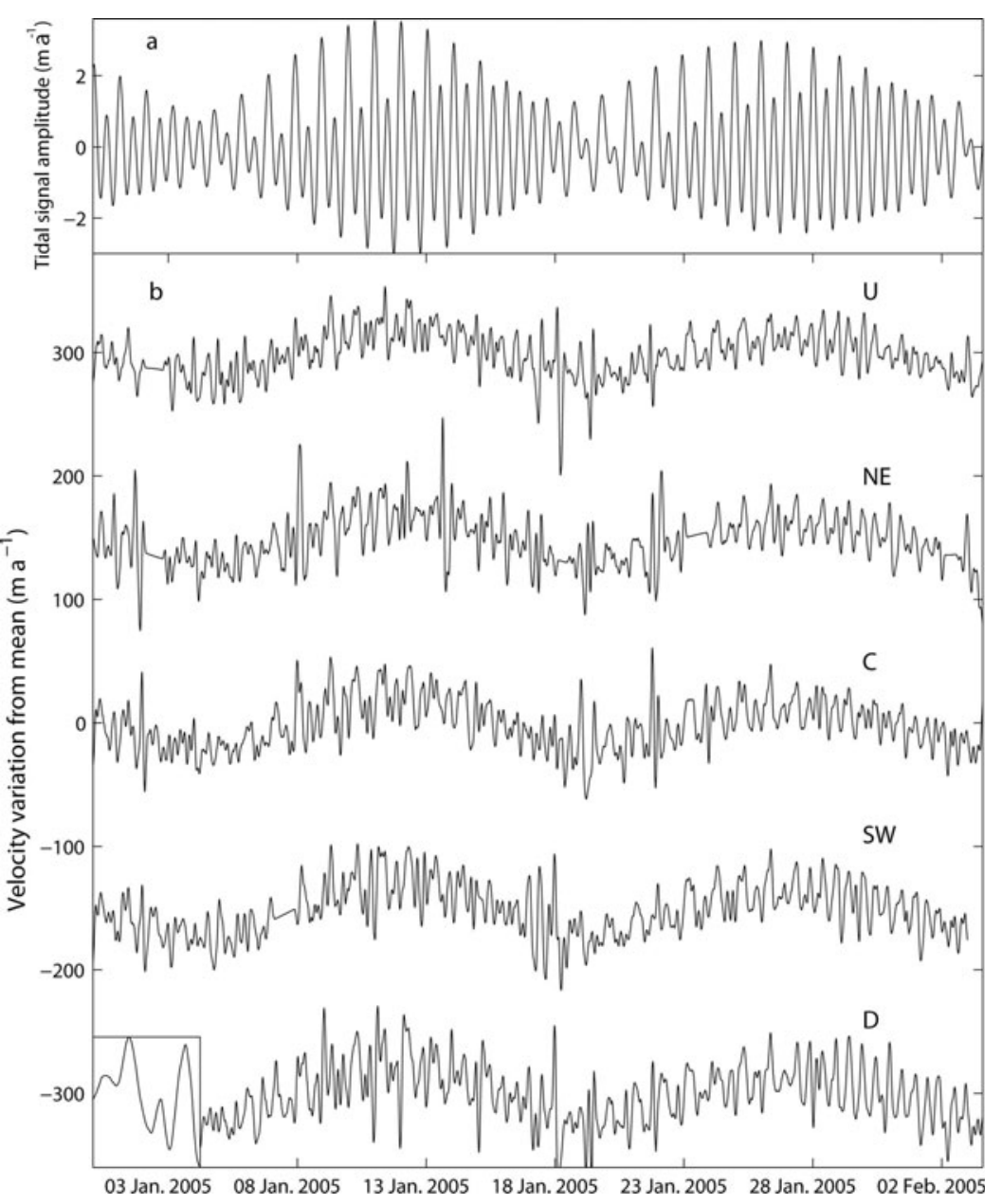

Fig. 5. (a) Tidal signal constructed with eight diurnal and semi-diurnal constituents and the lunar fortnightly and monthly (Mf and Mm) constituents for the period when the GPS measurements on Rutford Ice Stream were obtained. (b) The velocity variation from the mean velocity computed from the positions shown in Figure 3 as explained in the text. Top to bottom: U, NE, C, SW, D. For clarity, curves for NE and SW are shifted +150 and $-150 \mathrm{~m} \mathrm{a}^{-1}$, respectively, and curves for $U$ and $D$ are shifted +300 and $-300 \mathrm{~m} \mathrm{a}^{-1}$. The inset in the bottom left corner shows the computed velocity of SW during 10 January 2005, the same period as shown in the inset of Figure 3.

on the temporal aspects of the passive seismic record, i.e. whether a particular time is relatively active or not.

\section{TIDAL RECORD AT THE GROUNDING LINE}

To allow an assessment of the influence of ocean tides on the observed ice-stream velocity and basal seismicity variations, we generated tidal predictions of the surface elevation a short distance downstream of the grounding line, where the ice-shelf vertical displacement is driven by tides in the ocean beneath. The highest tidal amplitudes around Antarctica are found in the southern Filchner-Ronne Ice Shelf area, south of Henry and Korff ice rises. The spring-tide peak-to-peak range exceeds $7 \mathrm{~m}$ in the mouth of Rutford Ice Stream, and the major semi-diurnal constituents M2 and S2 dominate tidal records (Stephenson, 1984; Doake, 1992; Padman and others, 2002). A 56 day GPS data series of the vertical motion close to the grounding line (personal communication from G.H. Gudmundsson, 2005) has been analyzed with standard tidal analysis methods using the T-TIDE software package (Pawlowicz and others, 2002). The four main constituents are the $\mathrm{O} 1$ and $\mathrm{K} 1$ (diurnal) and M2 and S2 (semi-diurnal) constituents. Two other constituents are significant, Q1 and N2, and two constituents, K2 and P1, were inferred from S2 and K1, respectively (Pugh, 1987), using amplitude and phase relationships from the CATS02.01 tide model for Antarctic ice shelves and seas (Padman and others, 2002). The amplitude and phase of fortnightly and monthly tidal constituents could not be resolved from the original GPS record, so these were also obtained from the CATS02.01 tide model. Tidal predictions for the periods of the GPS and passive seismic experiments were constructed from these ten constituents. The resulting tidal prediction for the period of the GPS experiment is shown in Figure 5 a.

\section{GPS-DATA VELOCITY ANALYSIS}

\subsection{Velocity variations}

The along-flow horizontal position records (Fig. 3) as well as the results of Gudmundsson (2006) and Murray and others (2007) show that the velocity of Rutford Ice Stream is modulated by the ocean tides at the grounding line. We investigated the influence of tides by considering antenna velocity values, computed from the position data. The position data have a high temporal resolution (10 s) and the details of each antenna path will include a mixture of noise associated with the receiver and the data processing, wind-induced antenna fluctuations and real ice-flow variations. It was therefore necessary to filter any high-frequency signal. The following procedure was used to derive the antenna velocities. 


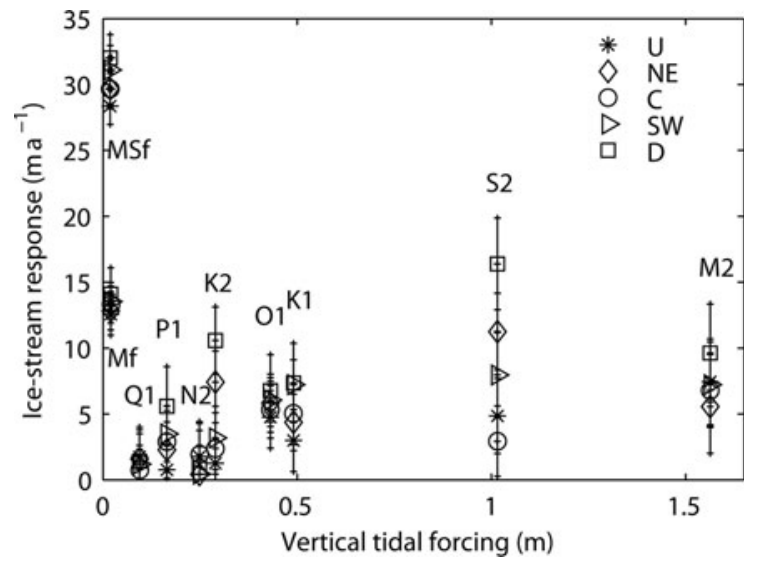

Fig. 6. The amplitude of each tidal component of the velocity records on the ice stream plotted against the corresponding amplitude on the ice shelf. Formal errors are shown as error bars at the $95 \%$ confidence level.

First, occasional data gaps were filled with values of a polynomial curve of degree 20, which was fitted through the data. This process does not add to the high-frequency signal, nor should it distort the fortnightly variation in the velocity. The records of receiver position were then filtered using a low-pass, finite impulse response (FIR) filter, with a cut-off frequency of $20 \mathrm{~min}$, and resampled every $10 \mathrm{~min}$. The velocity was then computed with a five-point numerical differentiation. The resulting velocity was finally filtered further with a 13-point running average, which is equivalent to low-pass filtering with a 2 hour cut-off frequency. This kept the decimation rate of the velocity records at $10 \mathrm{~min}$. The resulting velocity variation from the mean of all five stakes is shown in Figure 5b. The consistency of the results was tested by predicting the antenna positions using the computed velocities and comparing these with the measured position. Excellent agreement was found between the two datasets (the final position of each of the antennas was within $2 \%$ of the total movement over the period of 34.5 days). The error in the velocity is estimated to be $10 \mathrm{ma}^{-1}$, which is $\sim 3 \%$ of the mean velocity. The total variance of the velocity, in terms of standard deviation from the mean velocity, is shown in Table 1 . The largest variance is at D, and it decreases upstream.

\subsection{Frequency analysis}

The along-flow, horizontal velocity time series for all five stations (Fig. 5) were analyzed using fast Fourier transform (FFT) to indicate all the significant frequencies present in the data. All the power spectra were broadly similar, with by far the largest component at $\sim 0.067$ cycles $^{-1}$ ( 15 day period), two major modes at 1 cycle $^{-1}$, two at 2 cycles $^{-1}$ and smaller peaks at 3 and 4 cycles $d^{-1}$. In addition, the records at stations $\mathrm{C}, \mathrm{SW}$ and $\mathrm{D}$ have a significant frequency peak at 8 cycles $^{-1}$.

\subsection{Harmonic analysis for tidal species}

The general frequency analysis described above indicates that the GPS data are dominated by signals with typical ocean-tide frequency values. Hence, to allow a more rigorous comparison between the GPS data and the tidal record from the ice shelf, the GPS velocity records were analyzed specifically for the semi-diurnal, diurnal and fortnightly constituents present in the ice-shelf record using the T-TIDE software package (Pawlowicz and others, 2002). The datasets are too short to include the longer-period components such as monthly, semi-annual and annual, although analysis of a longer time series at this location demonstrates that these components are present (Murray and others, 2007). For consistency, the tidal prediction was also analyzed in the same way. Although the constituents used to generate the prediction are known, this approach means that uncertainties due to the limited record lengths, particularly in the longer-period constituents, should be similar for both the GPS velocity analysis and that of the tidal prediction. This allows a rigorous comparison to be made between the two datasets. It also gives some assessment of the proportion of the GPS record that can be explained by the anticipated ocean forcing, and how much must be attributed to other mechanisms, or to unresolved tidal components.

Two fortnightly constituents were specified in the harmonic analysis: MSf (14.76 day period), the lunisolar synodic fortnightly constituent; and Mf, the lunar fortnightly constituent (period 13.66 days). The main frequency in the observed time series is closer to 15 days. Globally, Mf is typically the dominant fortnightly constituent, due to direct gravitational forcing. However, due to non-linear interaction between M2 and S2 in shallow water (Pugh, 1987), MSf may be the dominant fortnightly term around much of Antarctica, particularly in the sub-ice-shelf regions. There are, at present, too few GPS or tilt data on the Ronne Ice Shelf near the grounding zone to separate Mf and MSf reliably and hence determine their respective magnitudes.

Three separate harmonic analyses were done using different fortnightly components: with MSf only, with Mf only and finally with both. The best result (giving the highest signal-to-noise ratio) was obtained when both constituents were used in the analysis. In this case, MSf was about two times larger in amplitude than Mf. The length of our velocity record is, however, only two fortnightly cycles, which is rather short to determine fortnightly characteristics accurately. Similar analysis of a 2 year velocity record nearby (Murray and others, 2007) showed an amplitude of MSf about five times larger than Mf. Adding the two fortnightly components in our analysis gives the total contribution at the period, which is $\sim 10-12 \%$ of the total velocity. This is in good agreement with similar data from Gudmundsson (2006), who analyzed the in-line position.

The harmonic analysis shows that the semi-diurnal, diurnal and the two fortnightly tidal components can account for up to $86 \%$ of the variance in the observed velocity record (Table 1). The remaining variance is due to limitations of this analysis due to the short length of the record, to other tides (including higher and lower frequencies) and noise and/or potential non-tidal contributions. The amplitudes of the constituents at each station are plotted against the corresponding constituent in the ice-shelf tidal signal in Figure 6, and the amplitudes of the six largest constituents are given in Table 1. The amplitude at fortnightly periods decreases upstream, with the amplitude at $\mathrm{D}$ and $\mathrm{C}$ of similar value but lower at $U$. The semi-diurnal constituents (M2, S2 and K2) have larger amplitudes than the diurnal ones, $\sim 4-12 \%$ of the total velocity. The diurnal components (O1, P1 and K1) have $\sim 3-5 \%$ amplitude compared to the total velocity. The estimates for the phase of each constituent have too high an error for conclusions to be drawn about the change in phase across or along the ice stream over the stake array. 
Figure 6 shows that for constituents with small amplitude on the ice shelf (Q1, P1, N2 and K2), the ice-stream response is smaller than for those of larger amplitude $(\mathrm{O} 1, \mathrm{~K} 1$, S2 and M2). Three further details of Figure 6 are also worth noting:

1. The response of the ice stream at the fortnightly periods is dominant, despite the relatively small vertical tidal forcing of that period on the ice shelf.

2. For the two largest constituents in the ice-shelf signal (semi-diurnal S2 and M2) the response of the ice stream is of similar magnitude, even though the amplitude of $\mathrm{M} 2$ is more than 1.5 times that of S2 on the ice shelf.

3. For most tidal frequencies, the errors in the harmonic analysis of the velocity data are such that the ice-stream response at each station cannot be claimed to differ significantly from that at any other site.

These observations have a number of implications. In the case of the fortnightly periods, which have a small amplitude on the ice shelf, the ice stream cannot solely be responding to that forcing but rather to the tidal range, which also has a period of $\sim 15$ days (two per lunar month of 29.5 days, or 14.75 days). Compare Figure $5 \mathrm{a}$ and $\mathrm{b}$ and observe that the velocity is high when the tidal range is large and low when the tidal range is smaller. Both autocorrelation of each of the velocity series, which indicates a periodicity of 15 days, and power spectra of FFT analysis, which shows by far the most energy in the 15 day period, support this. The second observation indicates that the amplitude of the forcing at the ice shelf is not the only factor controlling the ice-stream response. This has also been observed for the longer than fortnightly periods; semi-annual response of the ice stream does not scale with the forcing on the ice shelf (Murray and others, 2007). The third observation indicates that no significant difference in the ice-stream response to ocean tide forcing can be detected across an array of these dimensions $(6 \mathrm{~km} \times 6 \mathrm{~km})$ using the data acquisition, processing and harmonic analysis approaches we have employed.

\subsection{Time delay and strain rates over the array}

Cross-correlation between the different position records (at $10 \mathrm{~s}$ measurement resolution; Fig. 3) shows there is a time lag of $5 \pm 2 \mathrm{~min}$ between $C$ and $U$, a similar time lag between $D$ and $U$, and no discernible time lag across the glacier. This indicates that over the array there are changes in the propagation of the tidal modulation in the flow direction, but only between the furthest upstream site and the rest of the array. The modulation arrives simultaneously at D, SW, C and $N E$, but $5 \mathrm{~min}$ later at $U$, indicating a propagation velocity of $\sim 10 \pm 4 \mathrm{~m} \mathrm{~s}^{-1}$ between $U$ and the lower part of the grid which is moving synchronously. This is about an order of magnitude larger than Gudmundsson (2006) found by measuring phase changes between stations located at the grounding line, and 10, 20 and $40 \mathrm{~km}$ upstream from the grounding line, which indicated a propagation velocity of $1-2 \mathrm{~m} \mathrm{~s}^{-1}$. It is therefore likely that the propagation velocity is variable along the ice stream. Some areas appear to delay the signal less than other areas, such as the lower part of the measurement array.

The change in separation between stations NE and SW over the entire record is larger than between $U$ and $D$. Over the period of observations, SW and $\mathrm{C}$ move apart by $74.5 \mathrm{~cm}, \mathrm{C}$ and NE by $54.2 \mathrm{~cm}, \mathrm{U}$ and $\mathrm{C}$ by $3.7 \mathrm{~cm}$ and $\mathrm{C}$ and $\mathrm{D}$ by $14.6 \mathrm{~cm}$. The distance between the stations is $\sim 3 \mathrm{~km}$. This indicates extending flow in both horizontal directions, along and across the ice stream, with approximate strain rates of 0.00032 and $0.0023 \mathrm{a}^{-1}$, respectively. These values are similar to those measured previously in this area (e.g. Frolich and others, 1987).

\section{TIDAL CORRELATION WITH SURFACE VELOCITY AND BASAL SEISMICITY}

To compare the ice-flow variability and basal seismicity with the tidal record at the ice shelf, the time series were plotted together (Fig. 7). The ocean tide record is presented as the magnitude of the deviation from mean tide height (negative values of the ocean tide record (low tides in Fig. 5a) are drawn as positive values with a grey curve). It must be kept in mind that the tidal record is based on analysis of data from a different period and is not error-free. An example of the velocity record from one station during a 12 day period from spring tide to neap tide, as well as the first part of the seismic record on the same timescale are shown in Figure 7. It should also be kept in mind that the velocity perturbation propagates upstream with a velocity that can be variable along the ice stream. The cross-correlation of the position records indicates a propagation velocity of $10 \pm 4 \mathrm{~m} \mathrm{~s}^{-1}$, which would separate the velocity and the tidal signal by $0.8-1.8$ hours over the $40 \mathrm{~km}$ distance between the grounding line (assumed to be the location of the forcing) and the location of the measurements. Similar measurements over a larger area of the ice stream, from the grounding line to the measurement site, by Gudmundsson (2006) indicate a propagation velocity in the range $1-2 \mathrm{~m} \mathrm{~s}^{-1}$, which separates the two records by $5-11$ hours. The unknown separation of the records in Figure 7 makes it impossible to be certain whether a velocity or seismic peak occurs at high, falling, low or rising tide. However, comparing the two records without separation gives information about the occurrence of velocity or seismic peaks at equivalent times within the tidal cycle, as the separation can be assumed to be the same throughout the records.

Inspection of the entire record for all five stations, as well as the seismic record, reveals that there is no simple relationship between the ocean tide and the velocity and basal seismicity of the ice stream. In the velocity record there is, however, a distinct pattern visible, which is characterized by two velocity peaks during one tidal cycle (61-72\% of the tidal cycles have two velocity peaks). During about a third of the observed tidal cycles, there were three velocity peaks. For the basal seismicity record there are similarly two peaks in seismicity during $67 \%$ of the tidal cycles. The variability in seismic activity is larger than that in the velocity record.

Dividing the semi-diurnal tidal cycle into four equally long parts and counting the occurrence of peaks within each part gives information about relative timing of velocity or seismicity peaks within the tidal cycle. For the velocity record, simple peak counting reveals that about threequarters $(68-83 \%)$ of the first part of the tidal cycle coincides with velocity peaks, there are velocity peaks in $29-49 \%$ of the next part, $55-64 \%$ of the third part and $9-17 \%$ of the last part (the percentage ranges represent the values from the five stations). The five stations do not have the same response (e.g. the occurrence of three velocity peaks or a missing double peak does not happen concurrently at all sites). The 

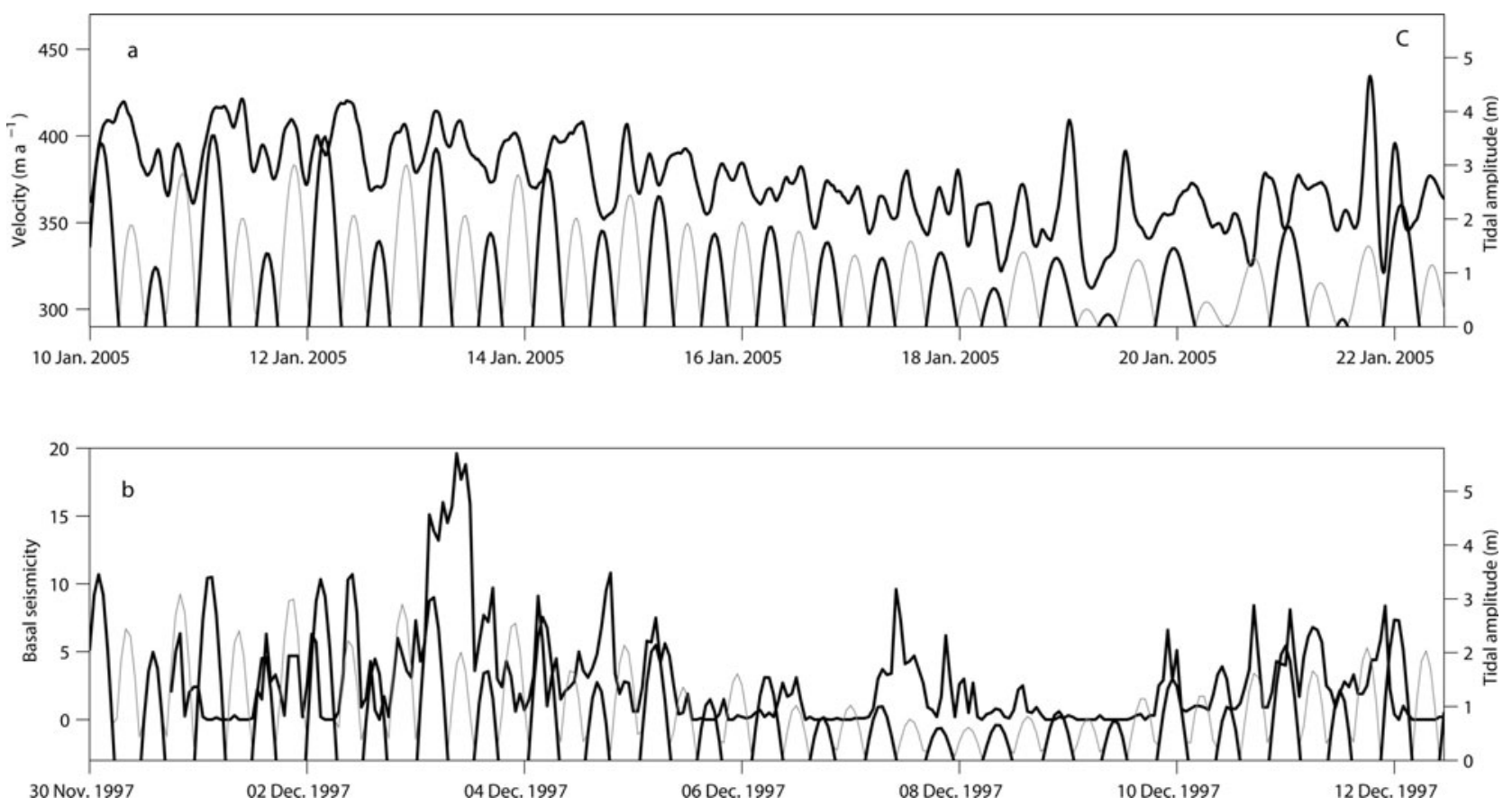

Fig. 7. (a) An example 12 day velocity record from $C$, drawn together with the modelled tidal record on the ice shelf. (b) The mean basal seismicity (events per hour) plotted on top of the modelled tidal record on the ice shelf. Only the first 12 days, while ten receivers were running, are shown. The predicted tidal record in both panels is shown as positive deviation from the mean. The high tide is plotted with a thick black curve, the low tide with a grey curve.

exceptions to the general behaviour (missing a double peak or three velocity peaks) occur randomly over the array, with more exceptions during neap tide than spring tide. The pattern between the velocity and the tidal record at the ice shelf is stronger during spring tide than neap tide. Similar counting of peaks in seismic activity within the four equally long parts of the tidal cycle shows that during 35 tidal cycles there are 24 peaks in the first part, 11 in the second, 24 in the third and 4 in the fourth part. The record of basal seismicity is not long enough, nor sufficiently complete, to determine with certainty whether the level of basal seismicity is greater during periods of spring tides. However, we note that the correlation with tides is still seen on some occasions during neap tide periods, as shown in the velocity record. Longer seismic records would be required to investigate this further.

The comparison of the velocity and seismic records with the tidal record at the ice shelf shows that both velocity and seismicity increase at the same time within the tidal cycle. The first and third parts of the semi-diurnal tidal cycle have highest velocity and seismicity, and the fourth part the lowest. The timing is, however, not precise, as can be seen in Figure 7 .

\section{DISCUSSION}

The observed flow of Rutford Ice Stream is strongly affected by the tides downstream of the measurement site. The fourth row in Table 1 shows that the semi-diurnal, diurnal and fortnightly ocean tides can account for up to $86 \%$ of the velocity variations evident in the GPS data. Comparison of rows three and four in Table 1 shows that the largest variation in velocity is at $D$ and this decreases upstream, but the tidal components can explain the largest percentage of the variance in the velocity at $U$. This indicates that contributions of noise, non-tidal disturbance and higher or lower tidal periods to the total velocity variance are not constant between the sites. The unexplained variance may well be the result of a combination of factors. Longer-period (e.g. monthly, semi-annual and annual) tidal components have been observed in a similar velocity record from the same location (Murray and others, 2007), but the records presented here are too short to analyze for them, and nonlinear forcing at grounding lines can lead to significant higher-frequency signals (Pedley and others, 1986), for which we have also not analyzed.

The analysis of the 6 week high-resolution and continuous-velocity records during the 2004/05 austral summer confirms the conclusion of Murray and others (2007) that the magnitude of the downstream velocity response at each frequency does not scale linearly with the amplitude of the corresponding vertical tidal forcing. Even though the measurements are made during solstice when the ice flow is slowest and the semi-diurnal variation is smallest (Murray and others, 2007), there are two or three velocity peaks observed during each tidal cycle.

The analysis of the velocity and seismic records from Rutford Ice Stream reveals some similarities and some differences between this ice stream and the Siple Coast ice streams. The position records, which have high temporal resolution (10s), exclude any stick-slip motion on Rutford Ice Stream. Increased velocity is observed during all parts of the tidal cycle, and therefore also during some of the falling tides, indicating that the same effect as on Bindschadler Ice Stream is acting (Anandakrishnan and others, 2003). In contrast to observations on Kamb Ice Stream, where there is anticorrelation between basal seismicity and mean flow speed and, on shorter timescales, correlation of basal seismicity and low tide on the ice shelf (Anandakrishnan and Alley, 1997a, b), we observe basal seismicity correlating 
with velocity and highest seismic activity during spring tide when the velocity is highest.

Rather than attempting to model all the different mechanisms that appear to be interacting simultaneously on Rutford Ice Stream, we make the following list which can contribute to the understanding of the transfer of the tidal force at the ice shelf to the flow of the ice stream, in particular, the increase in both velocity and seismic activity two (and sometimes three) times during each tidal cycle.

The tide level, which can vary up to $7 \mathrm{~m}$ during spring tide, changes the force balance in the grounding zone. Thomas (2007) proposes a simple force-perturbation model, which includes balance between the compressive force, resisting forces due to basal drag and marginal shear, and back forces caused by the depth of the sea and the ice shelf. In this model, ice-stream acceleration is favoured by low tides, but velocity changes are damped by changes in ice-shelf back pressure which are likely to favour acceleration at falling tide. The response is likely to be scaled by the amplitude of the tidal range.

Melting near the grounding line (Smith, 1996) may have an effect on the pressure in the subglacial drainage system and thereby basal motion. This mechanism could happen at tidal frequencies as warmer water is transported to the grounding line by tidal currents, and would not necessarily scale with tidal amplitude.

The tidal elevation itself may influence the basal shear stress and therefore affect the ice-stream motion. A model taking this effect into account has been shown to reproduce the fortnightly variation in in-line position (Gudmundsson, 2007). Reduced basal friction resulting from perturbations in basal shear stress may lead to reduced seismicity at high tide.

Doake and others (2002) considered the frictional drag of ocean currents on the underside of an ice shelf and the possibility for this to push and pull the ice at tidal fequencies. They concluded, however, that very high ice-water friction coefficients would be required for this mechanism to be significant. Also, although the sea-bed bathymetry near the grounding line of Rutford Ice Stream could well cause the ocean currents there to be complex, the overall ebb and flow of the tides is unlikely to generate the higher frequency responses (two and three per tide) that we observe in flow and seismicity. Therefore, it seems unlikely that this mechanism can explain our data.

Due to the pinning point in the centre of the grounding line, the rising and falling ice shelf may cause the ice stream to be partially ungrounded in areas upstream of the pinning point at low tide, as has been observed at Ekströmisen (Heinert and Riedel, 2007), reducing the basal resistive stress and increasing the velocity. Depending on how close the ice stream is to flotation in this area, this mechanism may or may not scale with the amplitude of the tide.

\section{CONCLUSION}

During the austral summer, Rutford Ice Stream flows at a speed of $\sim 370 \mathrm{~m} \mathrm{a}^{-1}\left(367-380 \mathrm{~m} \mathrm{a}^{-1}\right), 40 \mathrm{~km}$ upstream from the grounding line. Comparison between five velocity time series and the passive seismic record and the tidal record indicates a complicated response to the tidal forcing. Both the surface velocity and basal seismicity show two peaks, and sometimes three, during a tidal cycle, indicating that ocean tides at the grounding line modulate the ice-stream flow. The transfer of the ocean forcing up the ice stream is complicated and the effects of irregular grounding zone with areas of partial grounding (Rignot, 1998) and both spatially and temporally variable basal conditions (Smith, 1997a, b; Smith and others, 2007) contribute to the complexity. The variation in the velocity with fortnightly period has an amplitude of $\sim 10-12 \%$ of the total velocity, but at diurnal and semi-diurnal period the variation amplitude is $3-5 \%$ and $4-12 \%$, respectively. We summarize our observations as follows:

The flow is smooth, with no evidence of any stick-slip behaviour. The release of seismic energy is, however, not smooth, with variable levels of activity.

Both the velocity and the level of basal seismicity show increases that occur two times, sometimes three times, during each tidal cycle. The correlations are stronger during spring tide periods than neap tide.

Increase in velocity and basal seismicity correlates and occurs most frequently at equivalent times within the tidal cycle. The pattern is, however, not always consistent, indicating a complicated response of the ice stream to tidal forcing.

The amplitude of the ice-stream response at each tidal period does not scale with the corresponding forcing on the ice shelf.

There is little variation across the measurement array; the only significant difference detected was a 5 min phase lag between the upstream station $(U)$ and the rest of the array. This suggests a variable propagation velocity along the ice stream.

These observations suggest that numerous mechanisms are acting simultaneously. It is clear that the ice stream is sensitive to sea-level variations, at least at tidal frequencies. This sensitivity could have global implications, as the observed sea-level rise could be accelerated by increased ice-stream discharge.

\section{ACKNOWLEDGEMENTS}

This project was funded by the UK National Environmental Research Council (NERC) Antarctic Funding Initiative (AFI) (GR3/G005), the British Antarctic Survey (BAS) and NASA. Field support was provided by BAS. Equipment was supplied by NERC Geophysical Equipment Facility (loans 510 and 757). T.M. was supported by a Leverhulme Trust Fellowship and M.A.K. by a NERC postdoctoral research fellowship. We thank S. Abrahmas, A. Cottle, G. Kirk, J. Ralph, A. Taylor and J. Withers for help with data acquisition. We acknowledge the use of the software packages Track (GAMIT) and T-Tide for GPS data processing and harmonic analysis, respectively, and G. Weedon for discussions about time-series analysis. Thorough comments from three anonymous reviewers improved the quality of this paper considerably. 


\section{REFERENCES}

Anandakrishnan, S. and R.B. Alley. 1997a. Stagnation of Ice Stream C, West Antarctica by water piracy. Geophys. Res. Lett., 24(3), 265-268.

Anandakrishnan, S. and R.B. Alley. 1997b. Tidal forcing of basal seismicity of Ice Stream C, West Antarctica, observed far inland. J. Geophys. Res., 102(B7), 15,183-15,196.

Anandakrishnan, S. and C.R. Bentley. 1993. Micro-earthquakes beneath Ice Streams B and C, West Antarctica: observations and implications. J. Glaciol., 39(133), 455-462.

Anandakrishnan, S., D.E. Voigt, R.B. Alley and M.A. King. 2003. Ice Stream D flow speed is strongly modulated by the tide beneath the Ross Ice Shelf. Geophys. Res. Lett., 30(7) 1361. (10.1029/ 2002GLO16329.)

Bindschadler, R.A., M.A. King, R.B. Alley, S. Anandakrishnan and L. Padman. 2003a. Tidally controlled stick-slip discharge of a West Antarctic ice stream. Science, 301(5636), 1087-1089.

Bindschadler, R.A., P.L. Vornberger, M.A. King and L. Padman. 2003b. Tidally driven stick-slip motion in the mouth of Whillans Ice Stream, Antarctica. Ann. Glaciol., 36, 263-272.

Blankenship, D.D., S. Anandakrishnan, J.L. Kempf and C.R. Bentley. 1987. Microearthquakes under and alongside Ice Stream B, Antarctica, detected by a new passive seismic array. Ann. Glaciol., 9, 30-34.

Doake, C.S.M. 1992. Gravimetric tidal measurement on Filchner Ronne Ice Shelf. FRISP. Rep. 6, 34-39.

Doake, C.S.M., R.M. Frolich, D.R. Mantripp, A.M. Smith and D.G. Vaughan. 1987. Glaciological studies on Rutford Ice Stream, Antarctica. J. Geophys. Res., 92(B9), 8951-8960.

Doake, C.S.M. and 7 others. 2001. Rutford Ice Stream, Antarctica. In Alley, R.B. and R.A. Bindschadler, eds. The West Antarctic ice sheet: behavior and environment. Washington, DC, American Geophysical Union, 221-235. (Antarctic Research Series 77.)

Doake, C.S.M. and 6 others. 2002. Tide-induced lateral movement of Brunt Ice Shelf, Antarctica. Geophys. Res. Lett., 29(8), 1226. (10.1029/2001GL014606.)

Frolich, R.M., D.R. Mantripp, D.G. Vaughan and C.S.M. Doake. 1987. Force balance of Rutford Ice Stream, Antarctica. IAHS Publ. 170 (Symposium at Vancouver 1987 - The Physical Basis of Ice Sheet Modelling), 323-331.

Gudmundsson, G.H. 2006. Fortnightly variations in the flow velocity of Rutford Ice Stream, West Antarctica. Nature, 444(7122), 1063-1064.

Gudmundsson, G.H. 2007. Tides and the flow of Rutford Ice Stream, West Antarctica. J. Geophys. Res., 112(F4), F04007. (10.1029/2006JF000731.)

Heinert, M. and B. Riedel. 2007. Parametric modelling of the geometrical ice-ocean interaction in the Ekstroemisen grounding zone based on short time-series. Geophys. J. Int., 169(2), 407-420.
King, M. 2004. Rigorous GPS data-processing strategies for glaciological applications. J. Glaciol., 50(171), 601-607.

Legrésy, B., A. Wendt, I.E. Tabacco, F. Rémy and R. Dietrich. 2004. Influence of tides and tidal current on Mertz Glacier, Antarctica. J. Glaciol., 50(170), 427-435.

Murray, T., A.M. Smith, M.A. King and G.P. Weedon. 2007. Ice flow modulated by tides at up to annual periods at Rutford Ice Stream, West Antarctica. Geophys. Res. Lett., 34(18), L18503. (10.1029/2007GL031207.)

O'Neel, S., K.A. Echelmeyer and R.J. Motyka. 2001. Short-term flow dynamics of a retreating tidewater glacier: LeConte Glacier, Alaska, USA. J. Glaciol., 47(159), 567-578.

Padman, L., H.A. Fricker, R. Coleman, S. Howard and L. Erofeeva. 2002. A new tide model for the Antarctic ice shelves and seas. Ann. Glaciol., 34, 247-254.

Pawlowicz, R., B. Beardsley and S. Lentz. 2002. Classical tidal harmonic analysis including error estimates in MATLAB using T-TIDE. Comput. Geosci., 28(8), 929-937.

Pedley, M., J.G. Paren and J.R. Potter. 1986. The tidal spectrum underneath Antarctic ice shelves. J. Geophys. Res., 91(C11), 13,001-13,010.

Pugh, D.T. 1987. Tides, surges, and mean sea-level: a handbook for engineers and scientists. Chichester, Wiley.

Rignot, E. 1998. Radar interferometry detection of hinge-line migration on Rutford Ice Stream and Carlson Inlet, Antarctica. Ann. Glaciol., 27, 25-32.

Smith, A.M. 1991. The use of tiltmeters to study the dynamics of Antarctic ice-shelf grounding lines. J. Glaciol., 37(125), 51-58.

Smith, A.M. 1996. Ice shelf basal melting at the grounding line, measured from seismic observations. J. Geophys. Res. 101 (C10), 22,749-22,755.

Smith, A.M. 1997a. Basal conditions on Rutford Ice Stream, West Antarctica, from seismic observations. J. Geophys. Res., 102(B1), 543-552.

Smith, A.M. 1997b. Variations in basal conditions on Rutford Ice Stream, West Antarctica. J. Glaciol., 43(144), 251-261.

Smith, A.M. 2006. Microearthquakes and subglacial conditions. Geophys. Res. Lett., 33(24), L24501. (10.1029/2006GL028207.)

Smith, A.M. and 6 others. 2007. Rapid erosion, drumlin formation and changing hydrology beneath an Antarctic ice stream. Geology, 35(2), 127-130.

Stephenson, S.N. 1984. Glacier flexure and the position of grounding lines: measurements by tiltmeter on Rutford Ice Stream, Antarctica. Ann. Glaciol., 5, 165-169.

Stephenson, S.N. and C.S.M. Doake. 1982. Dynamic behaviour of Rutford Ice Stream. Ann. Glaciol., 3, 295-299.

Thomas, R.H. 2007. Tide-induced perturbations of glacier velocities. Global Planet. Change, 59(1-4), 217-224.

Zumberge, J.F., M.B. Heflin, D.C. Jefferson, M.M. Watkins and F.H. Webb. 1997. Precise point positioning for the efficient and robust analysis of GPS data from large networks. J. Geophys. Res., 102(B3), 5005-5017. 